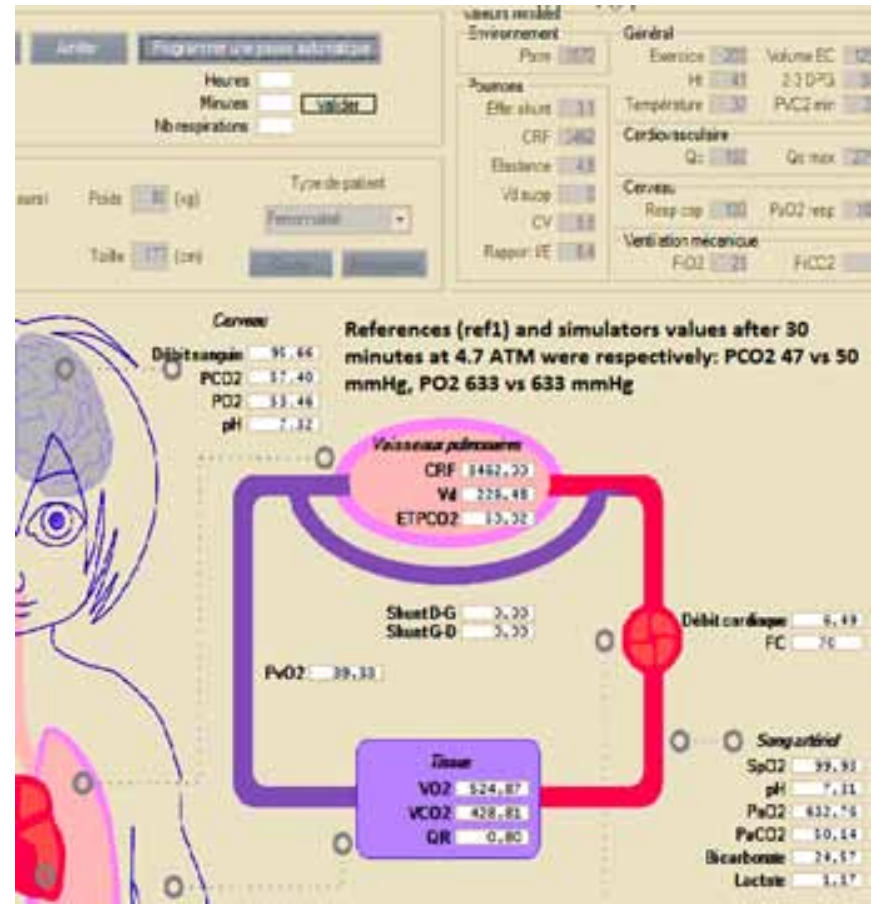

Abstract 999 Figure 2 Ventilation simulation at 4.7 ATM

Conclusion The cardiorespiratory simulator, SimulResp, delivered blood gases values within normal range. The next step will be to implement clinical scenarios to facilitate medical student training.

Reference (1) Cherry AD, Predictors of hypercapnia in immersed exercise at depth, JAP2008,106:316-325.

\section{REPEATED THERMO-STERILIZATION INFLUENCES THE RELIABILITY OF PEEP-VALVES}

doi:10.1136/archdischild-2012-302724.1000

JC Hartung, G Schmalisch, CC Roehr. Dept. Neonatology, Charité Universitätsmedizin Berlin, Berlin, Germany

Introduction PEEP valves are used to provide a preset positive endexpiratory pressure (PEEP) together with self-inflating bags (SIB). It has recently been shown that such valves may deliver unreliable PEEP. We hypothesized that material fatigue due to repeated thermo-sterilization was responsible for decreasing reliability of PEEP valves.

Methods Laboratory study of 10 factory new PEEP valves. Valves were tested before (measurement 1) and after 10, 20 and 30 (measurements $2,3,4$ ) cycles of routine thermo-sterilization for $7 \mathrm{~min}$ at $134^{\circ} \mathrm{C}$ by using a neonatal lung model (compliance $0.2 \mathrm{ml}^{*} \mathrm{kPa}^{-1}$ ). Settings were: peak inspiratory pressure (PIP) $=20$ and $40 \mathrm{~cm} \mathrm{H}_{2} \mathrm{O}$, $\mathrm{PEEP}=5$ and $10 \mathrm{~cm} \mathrm{H}_{2} \mathrm{O}$, respiratory rate $=40$ and $60 / \mathrm{min}$, flow $=81 /$ min. PEEP was recorded using a respiratory function monitor.

Results Before thermo-sterilization, a mean (SD) PEEP of 4.0 (0.9) and $7.7(1.0) \mathrm{cm} \mathrm{H}_{2} \mathrm{O}$ was delivered by the 10 valves when set to 5 and $10 \mathrm{cmH}_{2} \mathrm{O}$, respectively. One new valve only delivered $2.0(0.0)$ and $5.0(0.0) \mathrm{cm} \mathrm{H}_{2} \mathrm{O}$. Four of the 10 investigated valves showed relevant variations in PEEP ( $\mathrm{CV}>10 \%)$ throughout the thermo-sterilization process. Valve No. 8 completely lost its function after the second cycle of thermo-sterilization. $6 / 10$ valves maintained the ability to provide PEEP despite repeated autoclavation. Some valves showed tears or displacement of the rubber seal.

Conclusion The reliability of PEEP valves is affected by repeated thermo-sterilization. Valves should be tested before each use and substituted if necessary.

\section{CAN CLINICIANS PREDICT EARLY WHICH BABIES WOULD GO HOME ON OXYGEN: A CASE CONTROL STUDY}

doi:10.1136/archdischild-2012-302724.1001

'SSS Badrol, ${ }^{2 K}$ Quinn, ${ }^{2}$ S Gupta. 'Medical School, Newcastle University, Newcastleupon-Tyne; ${ }^{2}$ Neonatology \& Paediatrics, University Hospital of North Tees, Stockton-onTees, UK

Background Babies born at extreme gestation are prone to develop complications of prematurity including bronchopulmonary dysplasia (BPD). It is however very difficult to predict babies at risk of being discharged on home oxygen.

Aims To identify the possible contributing factors for chronic oxygen dependency among infants born before 28 weeks gestation. Methods Babies born before 28 weeks gestation between 2009 and 2011 and discharged home on oxygen (cases) from University Hospital of North Tees were identified. Matched control for gestation as close to the date of birth for each case was then identified from admission register. Demographic and clinical details pre \& post discharge were collected for cases \& controls and analysis for comparison done using SPSS $®$ version 19.

\section{Results}

- The mean gestation $26.5 \mathrm{vs} .25 .6$ weeks $(\mathrm{p}=0.170)$ and birth weight $915 \mathrm{vs} .828 \mathrm{~g}(\mathrm{p}=0.337)$ were similar between controls \& cases respectively.

- Babies discharged on home oxygen were dependent on oxygen for significantly longer period (62vs.31 days; $p=0.007$ ); received prolonged CPAP (25vs.12 days; $\mathrm{p}=0.01$ ) but difference in duration of mechanical ventilation was not significant (25vs.13 days; $\mathrm{p}=0.11$ ).

- Peak inspiratory pressures for cases were significantly higher compared to controls (30vs.19mm Hg; $\mathrm{p}=0.031$ ) but length of hospital stay was not different (87vs.80 days; $\mathrm{p}=0.477$ ).

- BPD rates $(p=0.001)$ and diuretic use $(p=0.029)$ in home oxygen group was significantly higher.

- The duration of home oxygen therapy was not affected by postnatal complications or respiratory support.

Conclusion Prolonged period of respiratory support, high peak inspiratory pressures and use of diuretics in extreme premature babies is correlated with discharge on home oxygen.

\section{MONITORING AND PREVENTION OF UNPLANNED EXTUBATIONS}

doi:10.1136/archdischild-2012-302724.1002

DK White, ME Harvey. Paediatric Intensive Care, Cambridge University Hospitals NHS Foundation Trust, Cambridge, UK

Background and Aims Unplanned Extubations (UE's) are potentially life threatening events ${ }^{1}$. They can result in traumatic reintubations which in turn can lead to tracheal damage. The monitoring and prevention of these incidents is of paramount importance to the safety of children in the paediatric intensive care unit (PICU).

Methods A previous audit of UE's had been conducted between August 2010 and April 2011 as we had noticed a sharp increase in incidence. Although the rate of $0.56 / 100$ ventilator days was within 